\title{
STAT3 plays an important role in DNA replication by turning on WDHD1
}

\author{
Yunying Zhou ${ }^{1,3,4}$ and Jason J. Chen ${ }^{2,4^{*}}$ (D)
}

\begin{abstract}
Background: Signal transducers and activators of transcription 3 (STAT3) is a transcription factor that plays a key role in many cellular processes such as cell growth and cancer. However, the functions and mechanisms by which STAT3 regulates cellular processes are not fully understood.

Results: Here we describe a novel function of STAT3. We demonstrated that STAT3 plays an important role in DNA replication. Specifically, knockdown of STAT3 reduced DNA replication while activation and ectopic expression of STAT3 promoted DNA replication. We further identified the WD repeat and HMG-box DNA-binding protein 1 (WDHD1), which plays an important role in DNA replication initiation, as a novel STAT3 target gene that mediated the DNA replication function of STAT3. We showed that STAT3 bind the promoter/up regulatory region of WDHD1 gene.
\end{abstract}

Conclusions: These studies identified a novel function of STAT3 that is mediated by its newly identified target gene WDHD1 and have important implications.

Keywords: STAT3, WDHD1, Transcription, DNA replication

\section{Background}

Signal transducers and activators of transcription (STAT) family members are transcription factors that mediate many cellular processes and involved in the pathogenesis of various human diseases [1]. STAT3 is a core member of the STAT protein family and plays a key role in many critical cellular processes such as proliferation, differentiation, survival, immunosuppression, angiogenesis and tumorigenesis $[2,3]$. Targeted disruption of the mouse Stat3 gene leads to early embryonic lethality [4]. STAT3 is essential for the differentiation of the TH17 helper T cells [5]. STAT3 is aberrantly activated in a variety of tumors, STAT3 signaling promotes cancer through inflammation, obesity, stem cells and the pre-metastatic niche $[3,6]$.

STAT3 activation is triggered primarily by interleukin 6 (IL-6) family cytokine receptor-associated Janus

*Correspondence: jxchen@sdu.edu.cn; joan0539@163.com

${ }^{2}$ Department of Microbiology, School of Basic Medical Sciences, Cheeloo College of Medicine, Shandong University, Jinan, Shandong, China

Full list of author information is available at the end of the article kinases (JAKs) $[7,8]$ as well as receptor tyrosine kinases such as epidermal growth factor receptor (EGFR) [9-12], and non-receptor tyrosine kinases such as SRC [13-16]; Phosphorylation of STAT3 on residue Y705 induces dimerization and results in its nuclear translocation and activation of the transcriptional regulator function. STAT3 may be further modified by phosphorylation on a serine residue (S727) to promote its full activation [17, 18]. Kinases responsible for STAT3 phosphorylation at S727 include the MAPK cascade [18]. IL-6 also increases the expression of STAT3 gene [19]. Toll-like receptors (TLRs) and microRNAs were recently identified to regulate JAK-STAT signaling in cancer $[3,20,21]$.

Activated STAT3 can up-regulate the transcription of numerous genes, many of these genes are its direct target $[1,22]$. STAT3 target genes include cyclin D1 [23], BclXL [24], c-Myc [25, 26], $\beta$-catenin [27], nuclear factor- $\mathrm{\kappa} B(\mathrm{NF}-\kappa \mathrm{K})$ [28]. In addition to its established role as a transcription factor in cancer, STAT3 regulates mitochondrion functions $[29,30]$ as well as gene expression through epigenetic mechanisms [3]. The process of DNA

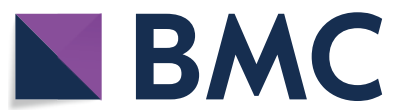

(c) The Author(s) 2021. This article is licensed under a Creative Commons Attribution 4.0 International License, which permits use, sharing, adaptation, distribution and reproduction in any medium or format, as long as you give appropriate credit to the original author(s) and the source, provide a link to the Creative Commons licence, and indicate if changes were made. The images or other third party material in this article are included in the article's Creative Commons licence, unless indicated otherwise in a credit line to the material. If material is not included in the article's Creative Commons licence and your intended use is not permitted by statutory regulation or exceeds the permitted use, you will need to obtain permission directly from the copyright holder. To view a copy of this licence, visit http://creativeco mmons.org/licenses/by/4.0/. The Creative Commons Public Domain Dedication waiver (http://creativecommons.org/publicdomain/ zero/1.0/) applies to the data made available in this article, unless otherwise stated in a credit line to the data. 
replication initiation consists of two steps: pre-replicative complex (pre-RC) assembly and activation [31]. WDHD1 (WD repeat and HMG-box DNA-binding protein 1) plays a role in both pre-RC assembly [32] and pre-RC activation [32-34]. WDHD1 is localized adjacent to replication foci, interacts with human primase-DNA polymerase/Mcm10 and is required for DNA synthesis [33, $35,36]$. A role for WDHD1 in G1 checkpoint control has recently been suggested [36, 37]. We have recently shown that WDHD1 plays a role in viral oncogene-induced rereplication [37].

In this report we described a novel biological function of STAT3. We showed that STAT3 played an important role in DNA replication. In addition, we identified WDHD1 as a STAT3 regulated target gene that mediated the DNA replication function of STAT3.

\section{Results}

\section{STAT3 plays a role in DNA replication}

Our recent studies demonstrated that both STAT3 and WDHD1 were up-regulated in oncogene overexpressing cells [37]. STAT family proteins recognize a consensus DNA binding motif of TTCC (C or G) GGAA (or generically TTN5AA) [38]. There are three putative STAT3 binding sites in the WDHD1 promoter/up regulatory region. Since WDHD1 plays a role in DNA replication, we reasoned that STAT3 might be involved in DNA replication by up-regulating WDHD1. To test this possibility, we knocked down STAT3 in MCF-7 cells by siRNAs and measured BrdU incorporation (Fig. 1). Since STAT3 knock-down could lead to cell arrest at the G1 phase of the cell cycle [39-41] and thus reduce BrdU incorporation, we synchronized cells at late G1/early S-phase by thymidine block before siRNA transfection and the effects of thymidine block and release of cell cycle were demonstrated in Additional file 1: Fig. 1a and b. DNA replication was measured after releasing from thymidine block (Fig. 1a and b). Notably, knock-down of STAT3 by siRNAs significantly reduced BrdU incorporation in MCF-7 cells, indicating that STAT3 plays a role in DNA replication (Fig. 1b). Similar results were observed in HeLa cells (Additional file 2: Fig. 2).

Next we examined the extent to which ectopic expression of STAT3 would facilitate DNA replication. For this, we transfected MCF-7 cells with plasmid encoding STAT3. To avoid the potential effect of STAT3 on G1/S phase transition, cells were thymidine blocked before transfection. After transfection and releasing from the block, DNA replication was measured. As shown in Fig. 1c, STAT3 expression was significantly increased after transfection with the STAT3 plasmid (left panel), and DNA replication was also significantly increased (Fig. 1c and quantified in the lower right panel). We also examined whether treatment of cells by the physiological activator of STAT3 could increase DNA replication. For this, thymidine blocked MCF-7 cells were treated with IL-6 and BrdU incorporation was measured (Fig. 1d). As expected, IL- 6 treatment led to an increase in both steady-state level and phosphorelated form of STAT3 (Upper left panel), more importantly, DNA replication was also significantly increased (Fig. 1c and quantified in the lower right panel).

\section{WDHD1 expression is regulated by STAT3}

Having demonstrated a role for STAT3 in DNA replication, we wanted to explore the mechanism by which STAT3 facilitates replication. Since STAT3 is a transcription factor, it is likely that STAT3 facilitates DNA replication by regulating a gene whose product involves in DNA replication. WDHD1 is certainly a potential candidate to mediate DNA replication function for STAT3. We therefore investigated the possibility that WDHD1 is a transcriptional target gene for STAT3. As mentioned and shown, both STAT3 and WDHD1 were upregulated in HPV oncogene E7 expressing cells (Fig. 2a). Upon treating MCF-7 cells with STAT3 activator IL-6, WDHD1 mRNA level went up (by 2.3-fold) (Fig. 2b). When treated with EGF, another growth factor known to activate STAT3, WDHD1 mRNA level also went up (by 1.4-fold) (Fig. 2c). Similar results were obtained in HeLa cells (Additional file 3: Fig. 3). Significantly, the WDHD1 mRNA levels in IL-6-treated cells were significantly down-regulated upon transfection with STAT3 siRNAs (Fig. 2d). Thus, we conclude that WDHD1 mRNA level is regulated by STAT3.

Next we examined whether the steady-state levels of WDHD1 protein is subjected to STAT3 regulation. As shown in Fig. 3a and consistent with mRNA levels, knockdown of STAT3 by siRNAs reduced the steadystate levels of WDHD1 protein (14-fold by si-STAT3-1 and 4-fold for si-STAT3-2) in MCF-7 cells (Fig. 3a). In contrast, siRNA knockdown of WDHD1 did not lead to a reduction in the steady-state levels of STAT3. Similar results were observed in HeLa cells (Additional file 4: Fig. 4). On the other hand, overexpression of STAT3 increased the steady-state levels of WDHD1 protein (Fig. 3b). Furthermore, IL-6 treatment also led to an up-regulation of WDHD1 protein levels (Fig. 3b). These results further support the notion that WDHD1 is a target for STAT3.

STAT3 binds to the WDHD1 promoter/up regulatory region To further establish the role of STAT3 in regulating WDHD1 expression, we examined the association of STAT3 at the promoter/up regulatory region of WDHD1. STAT family proteins recognize a consensus DNA 


\section{a Experimental design}

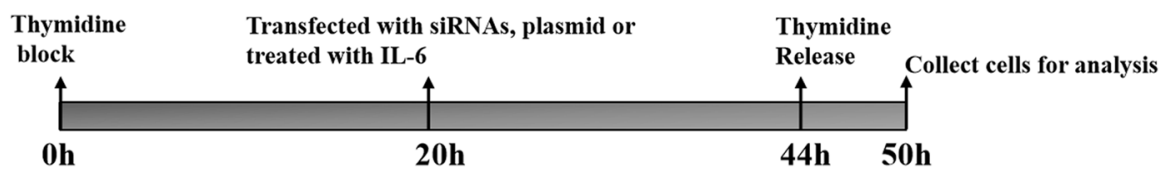

b

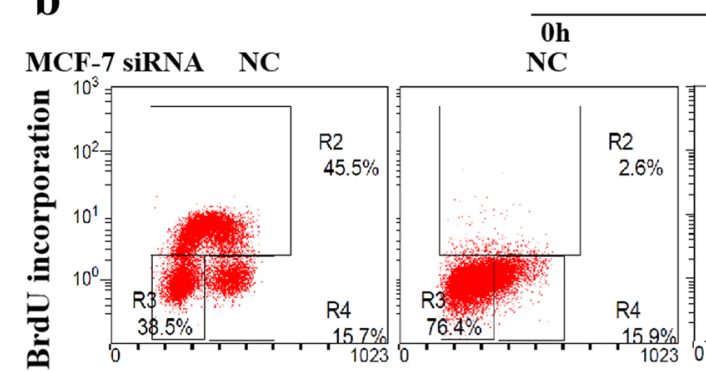

Thymidine block
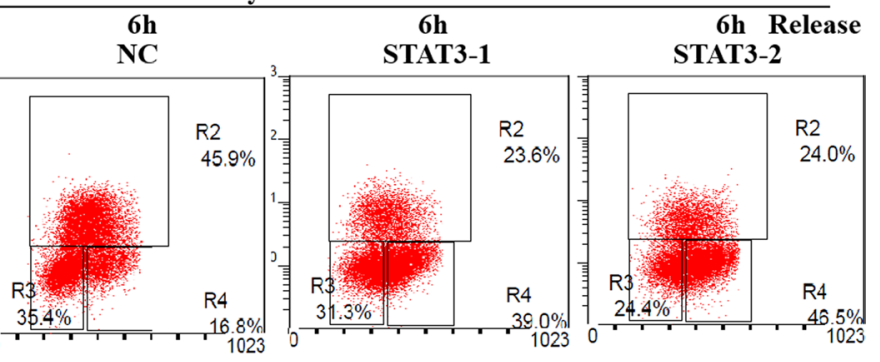

\section{DNA content}
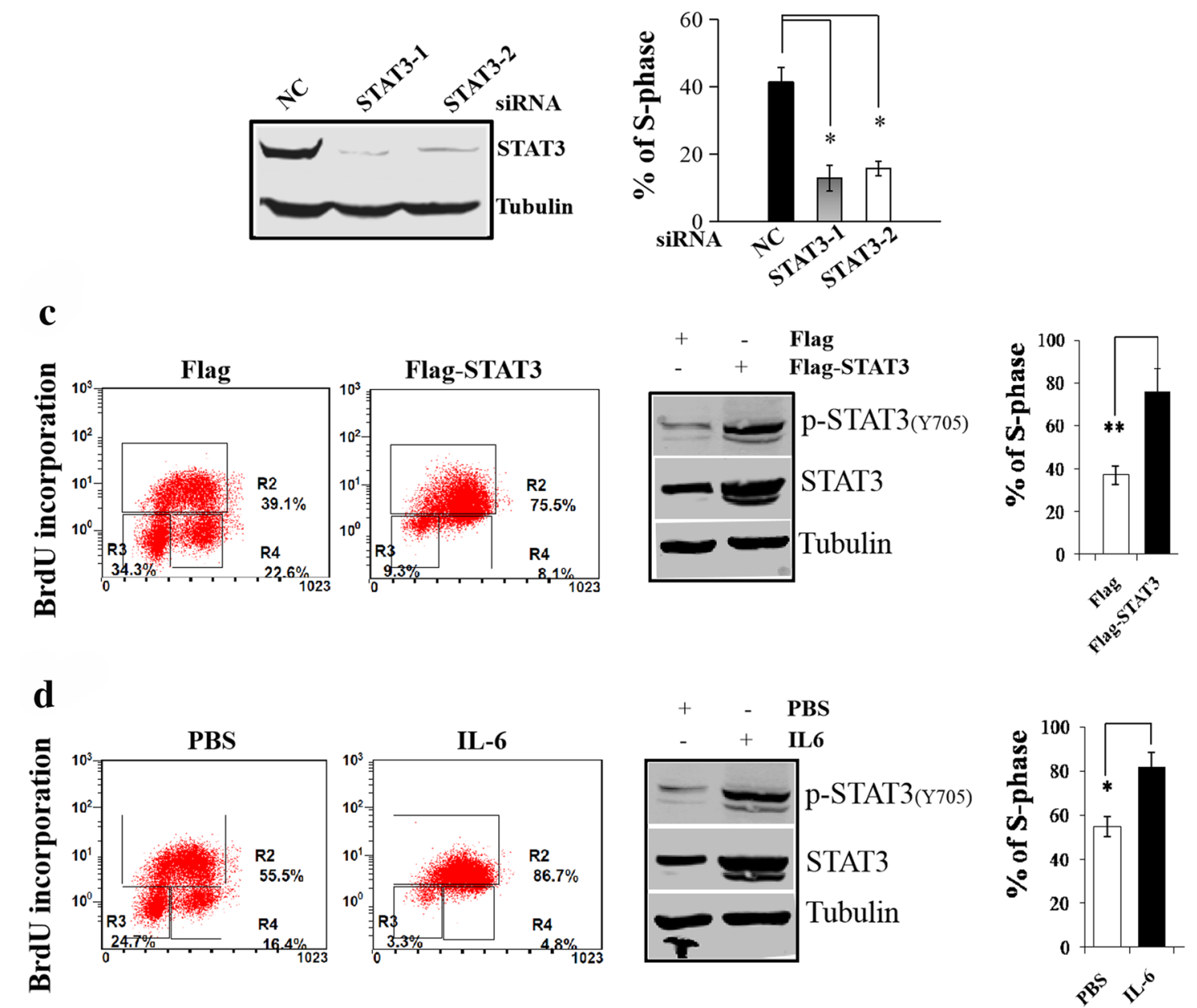

Fig. 1 STAT3 plays a role in DNA replication. a Experimental design. b-d After thymidine block, MCF-7 cells were transfected with siRNAs or plasmids, or treated with IL-6. After releasing, cells were stained with BrdU and analyzed by flow cytometry. Western blots were performed using transfected cell extracts without thymidine treatment. A representative experiment of 3 was shown. $\mathbf{b}$ siRNA transfection. c Plasmids transdaction. $\mathbf{d}$ IL-6 treatment 

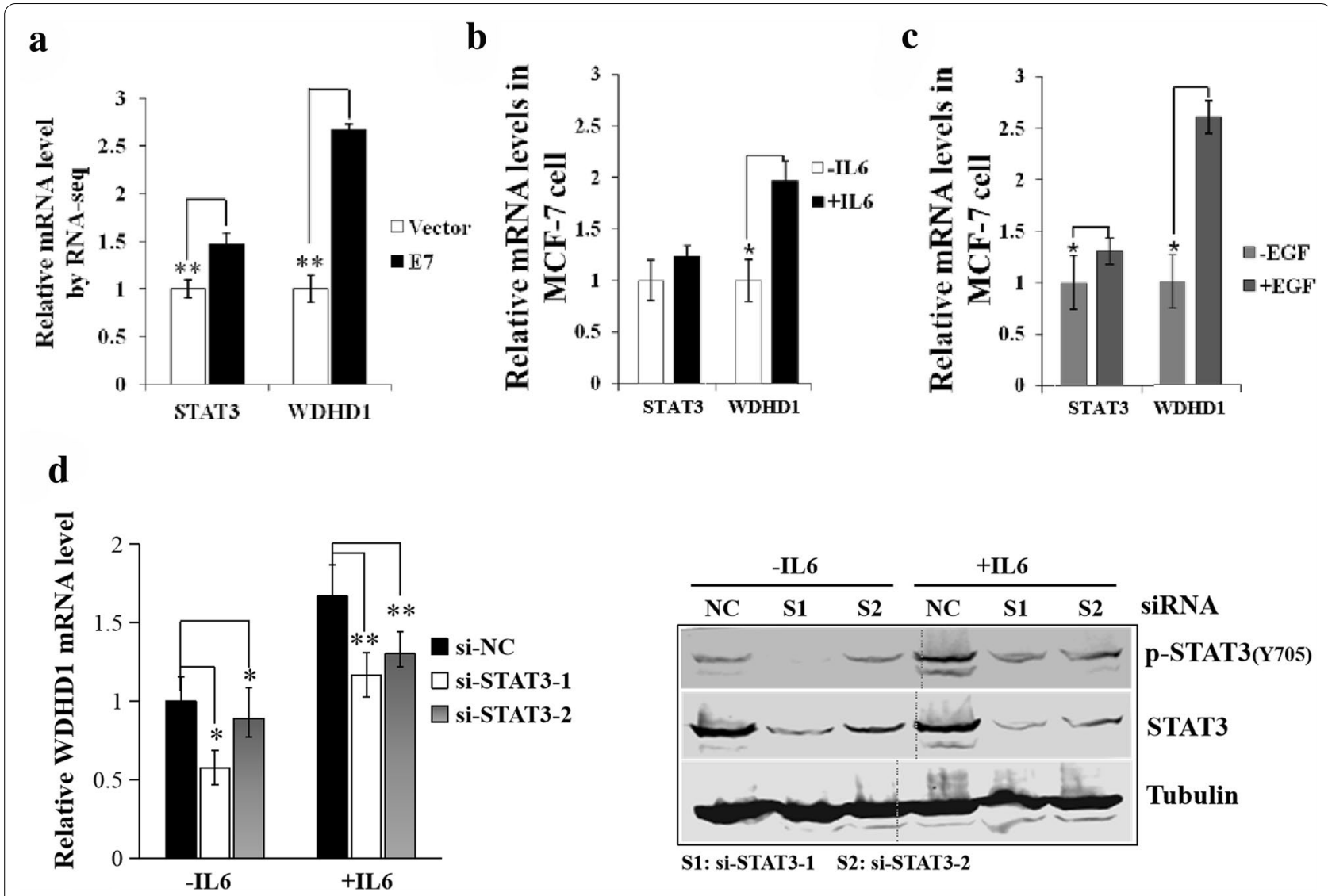

Fig. 2 WDHD1 expression is regulated by STAT3. a STAT3 and WDHD1 mRNA levels by RNA-seq. b STAT3 and WDHD1 mRNA levels in IL-6 treated MCF-7 cells determined by real-time-PCR analysis. c STAT3 and WDHD1 mRNA levels in EGF treated MCF-7 cells determined by real-time-PCR analysis. d WDHD1 mRNA levels in IL-6 treated, STAT3 siRNA transfected MCF-7 cells were determined by real-time-PCR analysis (Left panel). The steady-state levels of STAT3 were determined by Western blot (Right panel). Data from a representative experiment of 3 were shown. Error bars reflect the standard deviations of the mean. ${ }^{*} p<0.05,{ }^{* *} p<0.01$. NC negative control

binding motif of TTCCC/GGGAA [38]. Three putative STAT3 binding sites, named SB1 to SB3, were identified in the WDHD1 promoter/up regulatory region (Fig. 4a). ChIP assays were performed to examine the potential association of STAT3 with these putative binding sites. c-Fos served as a positive control as STAT3 has been shown by ChIP assay to bind and up-regulate c-Fos expression [42, 43]. Significantly, STAT3 bound to all three of putative binding sites in the wdhd1 promoter/ up regulatory region in MCF-7 cells at varying levels (Fig. 4b). It bound SB1 the most efficiently, to SB2 weakly, and to SB3 with reduced efficiency. Interestingly, in HeLa cells, STAT3 bound to SB1, SB3 but not SB2 (Additional file 5: Fig. 5). These results demonstrate an association of STAT3 to the wdhd1 promoter/up regulator region.

\section{WDHD1 can functionally rescue defect in DNA replication and re-replication caused by STAT3 knockdown}

As a STAT3 target functioning in DNA replication, WDHD1 should be able to rescue the DNA replication defect caused by STAT3 knockdown. We therefore overexpressed WDHD1 in cells STAT3 has been knocked down. For this, MCF-7 cells were synchronized at the late G1/early S-phase of the cell cycle with thymidine, transfected with STAT3 targeting siRNAs, then transfected with WDHD1 plasmid, DNA replication was examined. Significantly, expression of WDHD1 rescued DNA replication reduction caused by STAT3 knockdown (from $14.2 \%$ to $44.7 \%$, Fig. 5 a). These results demonstrate that WDHD1 can functionally replace STAT3 for its DNA replication activity and provide further evidence that WDHD1 is a target for STAT3.

Our data presented in this manuscript suggest a model where STAT3 binds to the promoter/up regulatory region of WDHD1, turns on its transcription. WDHD1 in turn participates DNA replication (Fig. 5b). These studies identified a novel function of STAT3 that is mediated by its target gene WDHD1 and have important implications. 


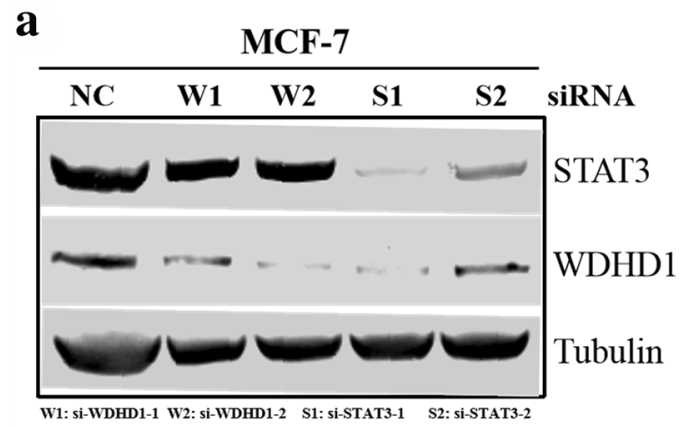

b

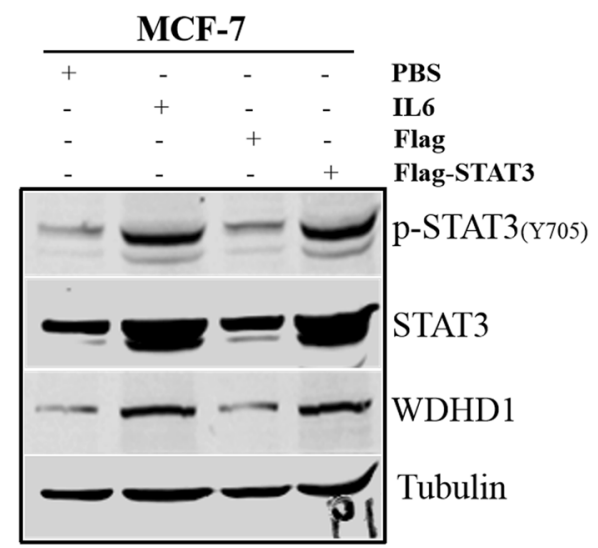

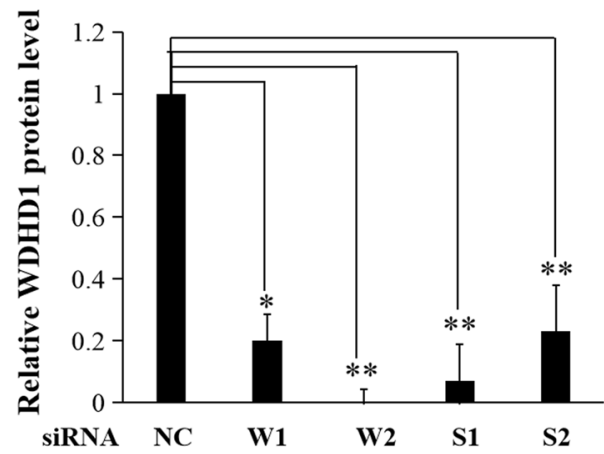

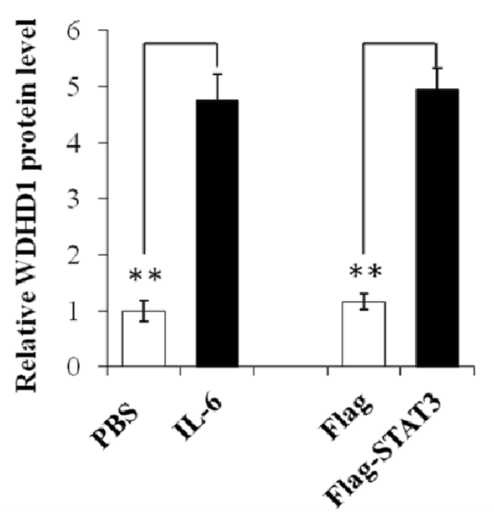

Fig. 3 The steady-state level of WDHD1 is regulated by STAT3. a The WDHD1 protein levels in MCF-7 cells were examined by Western blotting after siRNA transfection (Left panel). Data were summarized. b The WDHD1 protein levels in MCF-7 cells were examined by Western blotting after IL-6 treatment or transfection with STAT3 plasmid (Left panel). Data were summarized (Right panel). Data from a representative experiment of 3 were shown. Error bars reflect the standard deviations of the mean. ${ }^{*} p<0.05,{ }^{* *} p<0.01$. NC negative control

\section{Discussion}

STAT3 mediates many cellular processes and involves in the pathogenesis of various human diseases, including cancer. As a transcription factor, numerous transcriptional targets have been identified for STAT3 [44], these include c-Fos [43], HIF- $1 \alpha$ [45] and cyclin D1 [46, 47]. Our data support the notion that STAT3 regulates WDHD1 transcription and therefor promotes DNA replication. Interestingly, both STAT3 and WDHD1 have been implicated in cell cycle checkpoint control, epithelial-mesenchymal transition, tumor growth and metastasis [36, 37, 48, 49] and reviewed in [50, 51]. It would be interesting to examine whether STAT3 performs these functions through WDHD1. In addition to the above described activities, WDHD1 has also been implicated in the post-transcriptional step of the centromeric silencing pathway [52], chromosome congression by regulating the assembly of centromere Protein A (CENP-A) at centromeres [53], homologous recombination repair by regulating DNA end resection $[54,55]$, and the stability of Histone Acetyltransferase
Gcn5 and histone $\mathrm{H} 3$ acetylation [56]. As a regulator of WDHD1, it is important to examine whether STAT3 is also involved in these biological processes.

How STAT3 regulates WDHD1 transcription remains to be examined. We have found that STAT3 bound WDHD1 promoter/up regulatory region at three sites. We therefore speculate that STAT3 regulates WDHD1 transcription through direct binding to its promoter/ up regulatory region. In addition to act as a traditional transcription factor, STAT3 may regulate WDHD1 expression through epigenetic mechanisms. Future studies will explore this possibility.

A recent study showed that Cdc6 could be induced by STAT3 signaling [57]. As Cdc6 is also play a role in DNA replication initiation, it may contribute to the DNA replication activities identified for STAT3 in this study. Notably, the replication protein A $32 \mathrm{kDa}$ subunit (RPA p32) binds STAT3 and regulates STAT3 transcriptional activity [58]. RPA p32 has important functions in DNA replication. It remains to be explored 


\section{$\mathbf{a}$}

Transcription starting site of WDHD1

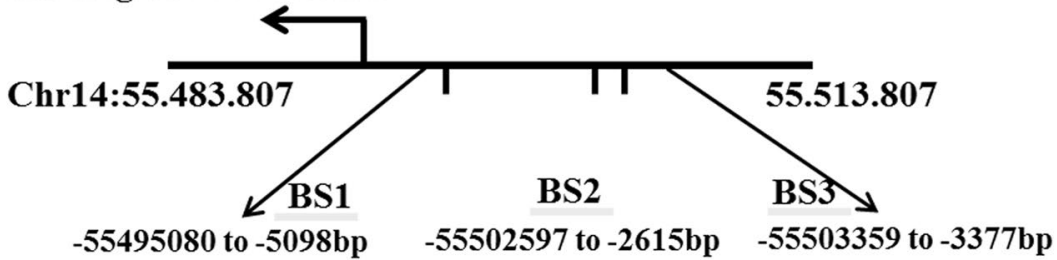

Binding Position Binding Sequence

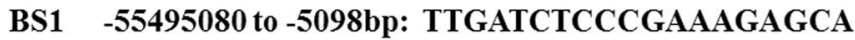

BS1 -55502597 to -2615bp: GCCATTTCCAAGAAACACC

BS1 -55503359 to $-3377 \mathrm{bp:}$ GCCATTCCTGGGAAATTTT

b

Chip assay: anti-STAT3

STAT3 binding sites on wdhd1 promoter
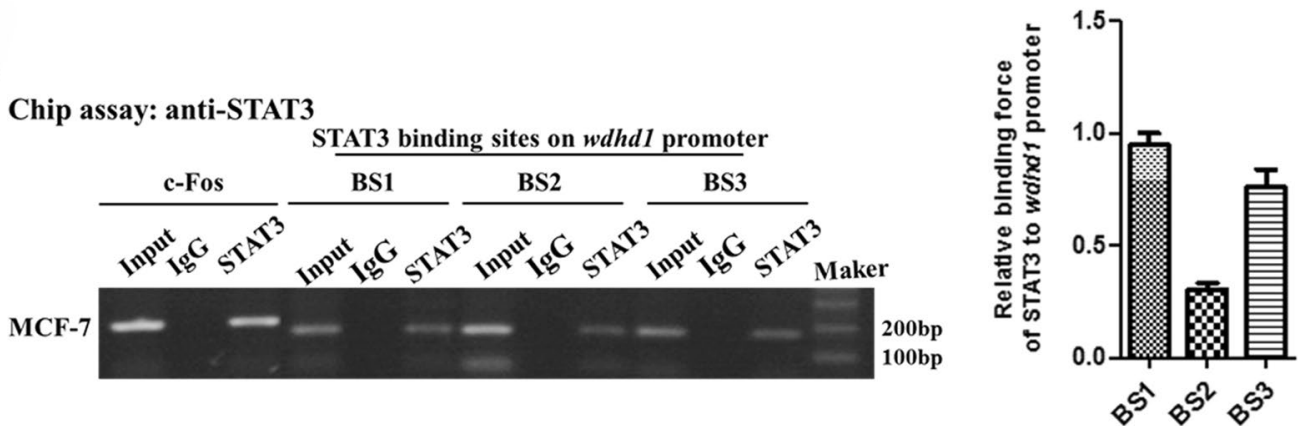

Fig. 4 STAT3 binds to WDHD1 promoter/up regulatory region region. a Three putative STAT3 binding sites (SB), named SB1 to SB3, were identified in the WDHD1 promoter/up regulatory region. $\mathbf{b}$ Immunoprecipitations were performed using anti-STAT3 or control IgG antibodies. PCR was performed with c-Fos or WDHD1 primers. Data from a representative experiment of 3 were shown (Left panel) and summarized (Right panel)

the extent to which STAT3 performs its DNA replication function through Cdc6 and RPA p32.

\section{Conclusions}

In this study, we provide evidence that STAT3 plays an important role in DNA replication. To the best of our knowledge, this is a first report for a role in DNA replication regarding STAT3. DNA replication is a fundamental activity for a living cell and identification of DNA replication function for STAT3 has important implications.

\section{Materials and methods}

\section{Cell culture}

Human breast cancer MCF-7 cells (American Type Culture Collection (ATCC), HTB-22) and cervical cancer HeLa cells (ATCC, CCL-2) were grown in Dulbecco's modified Eagle's medium supplemented with $10 \%$ fetal bovine serum (FBS) and incubated at $37{ }^{\circ} \mathrm{C}$ in a humidified atmosphere of $5 \% \mathrm{CO}_{2}$.

\section{Real-time PCR}

Total RNA was isolated with an RNeasy kit (Qiagen) from MCF-7 and HeLa cells and their correspondent targeting siRNA expressing cells according to the manufacturer's instruction. cDNA was synthesized with a Superscript VILO cDNA synthesis kit (Invitrogen). The iTaq Universal SYBR Green Supermix (Bio-Rad) was used for real-time PCR (qRT-PCR) in the Bio-Rad CFX96 Touch Real-Time PCR Detection system. Data were analyzed using the $2-\Delta \Delta \mathrm{Ct}$ method.

\section{Chromatin immunoprecipitation assay}

Chromatin immunoprecipitation (ChIP) assay was performed using the ChIP assay kit from Millipore following the manufacturer's protocol. Immunoprecipitations were performed using anti-STAT3 or control IgG antibodies. PCR was performed with the Simple ChIP Human c-Fos Promoter Primers (Cell Signaling, \#4663) that has been shown to interact directly with STAT3 $[42,43]$ and with the primers designed from the 

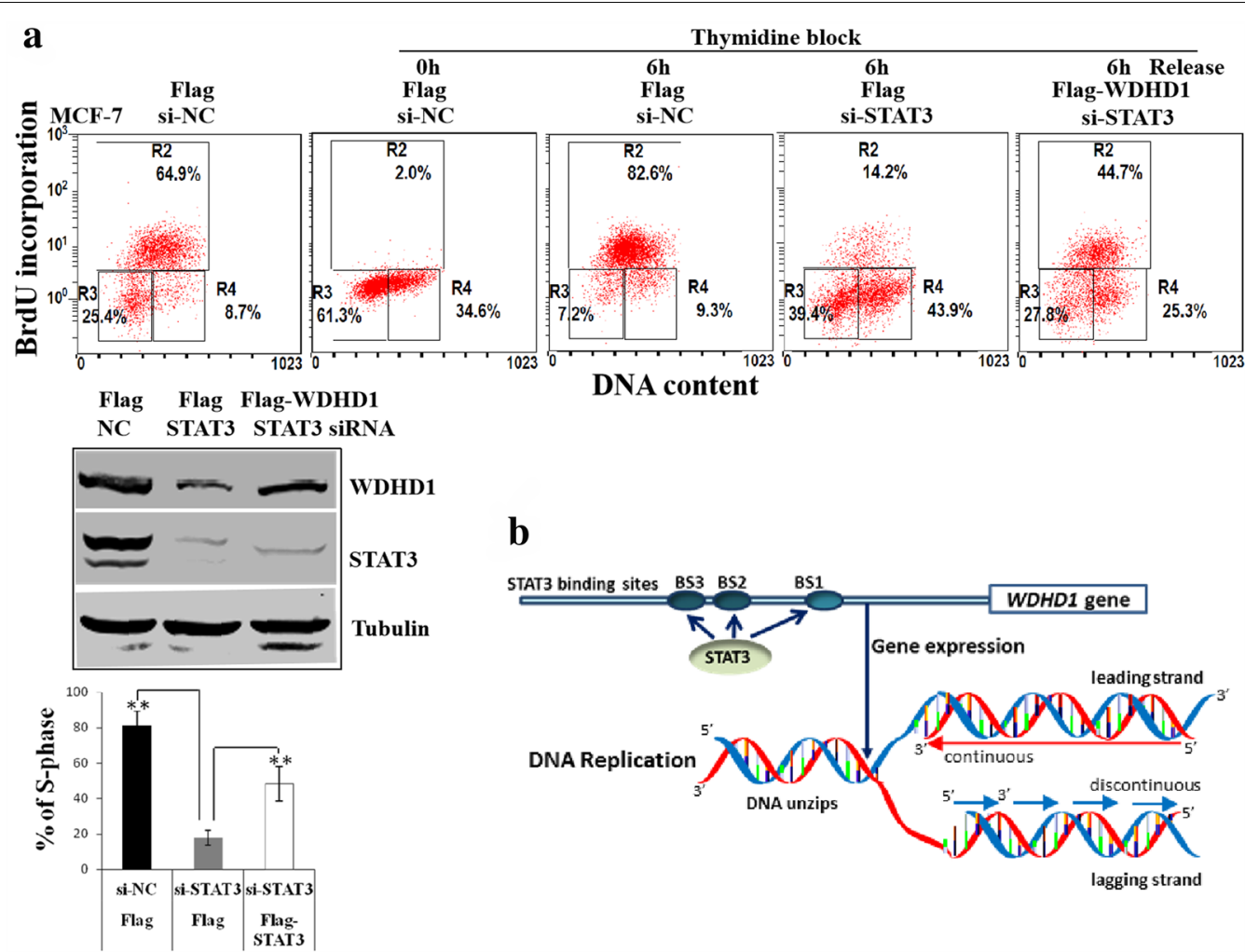

b

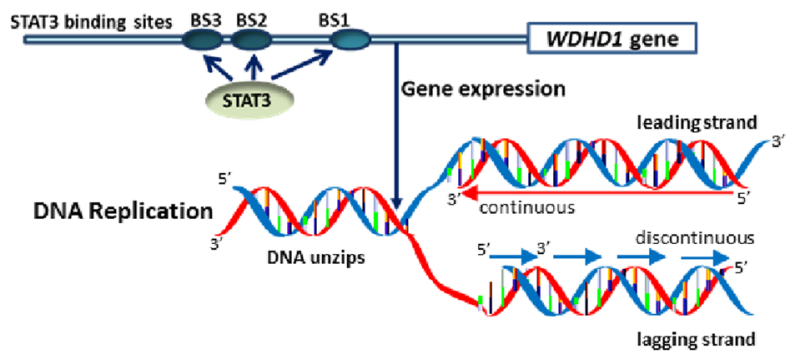

Fig. 5 Overexpression of WDHD1 rescued DNA replication reduction induced by STAT3 knocking down. a After thymidine block and siRNA transfection, MCF-7 cells were released, transfected with WDHD1 plasmid, stained with BrdU and analyzed by flow cytometry. a representative experiment of 3 was shown (Upper panel). The stability of STAT3 and WDHD1 was monitored by immunoblotting analyses (Middle panel). Data were summarized (Lower panel). b Proposed model. STAT3 binds to the promoter/regulatory region of WDHD1, turns on its transcription. WDHD1 in turn participates DNA replication

Table 1 The sequence of siRNA duplexes

\begin{tabular}{ll}
\hline Gene & Sequence (from $\mathbf{5}^{\prime} \mathbf{- 3}^{\prime}$ ) \\
\hline si-STAT3-1 & CAGGGUGUCAGAUCACAUGGGCUAA \\
si-STAT3-2 & GGACGACUUUGAUUUCAACTT \\
si-WDHD1-1 & GCAUGUACCCUAAGAAUAA \\
si-WDHD1-2 & GCAAAGUUAUGGAAAGUAU \\
\hline
\end{tabular}

sequences of the human WDHD1 promoter/up regulatory region gene.

\section{siRNAs and transfection}

Cells were transfected with a final concentration of $20 \mathrm{nM}$ siRNA per target gene (Table 1) using Lipofectamine 2000 transfection reagent (Invitrogen) according to the manufacturer's instructions. For gene knockdown analysis, cells were harvested $48 \mathrm{~h}$ post-transfection and specific protein levels were analyzed by immunoblot. For cell cycle analysis, MCF-7 cells were transfected with $20 \mathrm{nM}$ siRNA for $24 \mathrm{~h}$ after blocked with thymidine for $20 \mathrm{~h}$.

\section{Western-blot}

To obtain total protein, cell extraction was prepared in lysis buffer (10 mM Tris [pH 7.4], 1\% SDS, and $1.0 \mathrm{mM}$ sodium orthovanadate). The protein concentration was measured by the bicinchoninic acid (BCA) protein assay reagent (Pierce) and confirmed by Coomassie blue staining of membranes after blotting. Equal amounts of protein from each cell lysate were separated in an SDS polyacrylamide gel (PAGE) and transferred onto a nitrocellulose filter membrane (NC) membrane. Membranes were blotted with antibodies against WDHD1 (abcam, ab72436), STAT3 (Cell Signaling, 4904S), PhosphoSTAT3 (Tyr705) (Cell Signaling, \#9145), and tubulin (Sigma, T-4026).

\section{Flow cytometry}

For the bromodeoxyuridine (BrdU) labeling experiment, BrdU (Final $20 \mu \mathrm{M}$ ) was added to the medium $2 \mathrm{~h}$ before collection of cells. Cells were then harvested and fixed in $70 \%$ ethanol. The cells were permeabilized with $2 \mathrm{~N} \mathrm{HCl}-0.5 \%$ Triton X-100, neutralized 
with $0.1 \mathrm{M}$ sodium tetraborate, stained with monoclonal anti-BrdU (BD Biosciences), and then with antimouse IgG F(ab)2-FITC (Sigma), and counterstained with PBS-7-AAD-RNase A. Flow cytometric analysis was performed on a BD FACSAria ${ }^{\mathrm{TM}}$ III sorter instrument equipped with BD FACSDiva ${ }^{\mathrm{TM}} 7.0$ software (BD Biosciences, New Jersey, USA). FITC $490 \mathrm{~nm}$ fluorescence was acquired in logarithmic amplification in FL1 and 7-AAD $650 \mathrm{~nm}$ fluorescence was acquired in linear amplification in FL3. Cell cycle analysis was done using Cytomics ${ }^{\mathrm{TM}}$ FC500 Flow Cytometry CXP 2.0.

\section{Statistical analysis}

Data were presented as means and standard deviations (SDs). The Student's $t$ test was used to compare the differences between means. $\mathrm{P}<0.05$ was considered significant.

\section{Supplementary Information}

The online version contains supplementary material available at https://doi. org/10.1186/s13578-020-00524-x.

Additional file 1: Figure 1. Time selection of thymidine block and release of cell cycle. a MCF-7 cells were blocked with thymidine for $0 \mathrm{~h}, 20 \mathrm{~h}$ and 24h. b After thymidine block for $20 \mathrm{~h}$, MCF-7 cells were released for $1 \mathrm{~h}, 2 \mathrm{~h}$, $3 h, 4 h, 5 h, 6 h, 8 h, 10 h$.

Additional file 2: Figure 2. STAT3 plays a role in DNA replication in HeLa cells. After thymidine block, HeLa cells were transfected with siRNAs targeting STAT3. After releasing, cells were stained with BrdU and analyzed by flow cytometry. Data from a representative experiment of 3 were shown (Upper panel) and summarized (Lower panel). Western blots were performed using transfected cell extracts without thymidine treatment.

Additional file 3: Figure 3. WDHD1 mRNA expression is regulated by STAT3 in HeLa cells. STAT3 and WDHD1 mRNA levels in IL-6 or EGF treated HeLa cells determined by real-time-PCR analysis. Data from a representative experiment of 3 were shown. Error bars reflect the standard deviations of the mean. ${ }^{*} p<0.05{ }^{* *} p<0.01$. NC negative control.

Additional file 4: Figure 4. The steady-state levels of WDHD1 is regulated by STAT3 in HeLa cells. a STAT3 and WDHD1 protein levels in HeLa cells were examined by Western blotting after siRNA transfection (Left panel). Data were summarized (Right panel). Data from a representative experiment of 3 were shown. Error bars reflect the standard deviations of the mean. ${ }^{*} p<0.05{ }^{* *} p<0.01$. NC negative control.

Additional file 5: Figure 5. STAT3 binds to WDHD1 promoter/up regulatory region in HeLa cells. Immunoprecipitations were performed using anti-STAT3 or control IgG antibodies. PCR was performed with c-Fos or WDHD1 primers. Data from a representative experiment of 3 were shown (Left panel) and summarized (Right panel).

\section{Abbreviations}

WDHD1: WD repeat and HMG-box DNA-binding protein 1; STAT: Signal transducers and activators of transcription; IL-6: Interleukin 6; JAKs: Janus kinases; EGFR: Epidermal growth factor receptor; TLRs: Toll-like receptors; NF-kB: Nuclear factor-KB; BrdU: Bromodeoxyuridine; FACS: Fluorescence-activated cell sorting; ChIP: Chromatin immunoprecipitation assay.

\section{Acknowledgements}

We thank Qishu Zhang, Lijun Qiao and Yafei Liu for technical support. We thank the members of the laboratory for helpful discussions.

\section{Authors' contributions}

YZ prepared the manuscript, she was the major contributor in performing the experiments. JC designed the study, prepared the manuscript, and approved the final manuscript. All authors read and approved the final manuscript.

\section{Funding}

This work was supported by the National Natural Science Foundation of China (Grant No. 81471944 and 81802761); Key Research and Development Program of Shandong Province (Grant No. 2019GSF107014); China Postdoctoral Science Foundation (2019M652405);Academic promotion programme of Shandong First Medical University (2019QL024).

\section{Availability of data and materials}

All datasets generated for this study are included in the article/supplementary material.

\section{Ethics approval and consent to participate}

Not applicable.

\section{Consent for publication \\ Not applicable.}

\section{Competing interests}

Authors declared that there were no competing financial interests in relation to the work described.

\section{Author details}

${ }_{1}^{1}$ Medical Research \& Laboratory Diagnostic Center, Jinan Central Hospital, Cheeloo College of Medicine, Shandong University, Jinan, Shandong, China. ${ }^{2}$ Department of Microbiology, School of Basic Medical Sciences, Cheeloo College of Medicine, Shandong University, Jinan, Shandong, China. ${ }^{3}$ Medical Research \& Laboratory Diagnostic Center, Central Hospital Affiliated To Shandong First Medical University, Jinan, China. ${ }^{4}$ The Cancer Research Center, Cheeloo College of Medicine, Shandong University, Jinan, Shandong, China.

Received: 2 October 2020 Accepted: 21 December 2020

Published online: 07 January 2021

\section{References}

1. Matsuda T, Muromoto R, Sekine Y, Togi S, Kitai Y, Kon S, Oritani K. Signal transducer and activator of transcription 3 regulation by novel binding partners. World J Biol Chem. 2015;6(4):324-32.

2. Bromberg J, Darnell JE JJ. The role of STATs in transcriptional control and their impact on cellular function. Oncogene. 2000;19(21):2468-73.

3. Yu H, Lee H, Herrmann A, Buettner R, Jove R. Revisiting STAT3 signalling in cancer: new and unexpected biological functions. Nat Rev Cancer. 2014;14(11):736-46.

4. Takeda K, Noguchi K, Shi W, Tanaka T, Matsumoto M, Yoshida N, Kishimoto T, Akira S. Targeted disruption of the mouse Stat3 gene leads to early embryonic lethality. Proc Natl Acad Sci USA. 1997;94(8):3801-4.

5. Yang XO, Panopoulos AD, Nurieva R, Chang SH, Wang D, Watowich SS, Dong C. STAT3 regulates cytokine-mediated generation of inflammatory helper T cells. J Biol Chem. 2007;282(13):9358-63.

6. Wake MS, Watson CJ. STAT3 the oncogene - still eluding therapy? Febs J. 2015;282(14):2600-11.

7. Hirano T, Nakajima K, Hibi M. Signaling mechanisms through gp130: a model of the cytokine system. Cytokine Growth Factor Rev. 1997;8(4):241-52.

8. Kishimoto T, Taga T, Akira S. Cytokine signal transduction. Cell. 1994;76(2):253-62.

9. Zhong Z, Wen Z, Darnell JE Jr. Stat3: a STAT family member activated by tyrosine phosphorylation in response to epidermal growth factor and interleukin-6. Science. 1994;264(5155):95-8.

10. Berclaz G, Altermatt HJ, Rohrbach V, Siragusa A, Dreher E, Smith PD. EGFR dependent expression of STAT3 (but not STAT1) in breast cancer. Int J Oncol. 2001;19(6):1155-60.

11. Park OK, Schaefer TS, Nathans D. In vitro activation of Stat3 by epidermal growth factor receptor kinase. Proc Natl Acad Sci USA. 1996;93(24):13704-8. 
12. Leaman DW, Pisharody S, Flickinger TW, Commane MA, Schlessinger J, Kerr IM, Levy DE, Stark GR. Roles of JAKs in activation of STATs and stimulation of c-fos gene expression by epidermal growth factor. Mol Cell Biol. 1996;16(1):369-75.

13. Cao X, Tay A, Guy GR, Tan YH. Activation and association of Stat3 with Src in v-Src-transformed cell lines. Mol Cell Biol. 1996;16(4):1595-603.

14. Matikainen S, Sareneva T, Ronni T, Lehtonen A, Koskinen PJ, Julkunen I. Interferon-alpha activates multiple STAT proteins and upregulates proliferation-associated IL-2Ralpha, c-myc, and pim-1 genes in human T cells. Blood. 1999;93(6):1980-91.

15. Puthier $\mathrm{D}$, Bataille $\mathrm{R}$, Amiot M. IL-6 up-regulates mcl-1 in human myeloma cells through JAK/STAT rather than ras/MAP kinase pathway. Eur I Immunol. 1999;29(12):3945-50.

16. Yu CL, Meyer DJ, Campbell GS, Larner AC, Carter-Su C, Schwartz J, Jove R. Enhanced DNA-binding activity of a Stat3-related protein in cells transformed by the Src oncoprotein. Science. 1995;269(5220):81-3.

17. Schuringa JJ, Schepers H, Vellenga E, Kruijer W. Ser727-dependent transcriptional activation by association of p300 with STAT3 upon IL-6 stimulation. FEBS Lett. 2001;495(1-2):71-6.

18. Levy DE, Darnell JE Jr. Stats: transcriptional control and biological impact. Nat Rev Mol Cell Biol. 2002;3(9):651-62.

19. Yang J, Liao X, Agarwal MK, Barnes L, Auron PE, Stark GR. Unphosphorylated STAT3 accumulates in response to IL- 6 and activates transcription by binding to NFkappaB. Genes Dev. 2007;21 (11):1396-408.

20. Kortylewski M, Kujawski M, Herrmann A, Yang C, Wang L, Liu Y, Salcedo R, Yu H. Toll-like receptor 9 activation of signal transducer and activator of transcription 3 constrains its agonist-based immunotherapy. Cancer Res. 2009;69(6):2497-505.

21. Hossain DM, Dos Santos C, Zhang Q, Kozlowska A, Liu H, Gao C, Moreira D, Swiderski P, Jozwiak A, Kline J, et al. Leukemia cell-targeted STAT3 silencing and TLR9 triggering generate systemic antitumor immunity. Blood. 2014;123(1):15-25.

22. Carpenter RL, Lo HW. STAT3 target genes relevant to human cancers. Cancers. 2014;6(2):897-925.

23. Cressman DE, Greenbaum LE, DeAngelis RA, Ciliberto G, Furth EE, Poli V, Taub R. Liver failure and defective hepatocyte regeneration in interleukin6-deficient mice. Science. 1996;274(5291):1379-83.

24. Yamauchi-Takihara K. Gp130-mediated pathway and left ventricular remodeling. J Cardiac Fail. 2002;8(6 Suppl):S374-8.

25. Yamanaka Y, Nakajima K, Fukada T, Hibi M, Hirano T. Differentiation and growth arrest signals are generated through the cytoplasmic region of gp130 that is essential for Stat3 activation. EMBO J. 1996;15(7):1557-65.

26. Shirogane T, Fukada T, Muller JM, Shima DT, Hibi M, Hirano T. Synergistic roles for Pim-1 and c-Myc in STAT3-mediated cell cycle progression and antiapoptosis. Immunity. 1999;11(6):709-19.

27. Hao J, Li TG, Qi X, Zhao DF, Zhao GQ. WNT/beta-catenin pathway upregulates Stat3 and converges on LIF to prevent differentiation of mouse embryonic stem cells. Develop Biol. 2006;290(1):81-91.

28. Yu Z, Zhang W, Kone BC. Signal transducers and activators of transcription 3 (STAT3) inhibits transcription of the inducible nitric oxide synthase gene by interacting with nuclear factor kappaB. Biochem J. 2002;367(Pt 1):97-105.

29. Wegrzyn J, Potla R, Chwae YJ, Sepuri NB, Zhang Q, KoeckT, Derecka M, Szczepanek K, Szelag M, Gornicka A, et al. Function of mitochondrial Stat3 in cellular respiration. Science. 2009;323(5915):793-7.

30. Gough DJ, Corlett A, Schlessinger K, Wegrzyn J, Larner AC, Levy DE. Mitochondrial STAT3 supports Ras-dependent oncogenic transformation. Science. 2009;324(5935):1713-6.

31. Bell SP, Stillman B. ATP-dependent recognition of eukaryotic origins of DNA replication by a multiprotein complex. Nature. 1992;357(6374):128-34.

32. Li Y, Xiao H, de Renty C, Jaramillo-Lambert A, Han Z, DePamphilis ML, Brown KJ, Zhu W. The involvement of acidic nucleoplasmic DNA-binding protein (And-1) in the regulation of prereplicative complex (pre-RC) assembly in human cells. J Biol Chem. 2012;287(51):42469-79.

33. Zhu W, Ukomadu C, Jha S, Senga T, Dhar SK, Wohlschlegel JA, Nutt LK, Kornbluth S, Dutta A. Mcm 10 and And-1/CTF4 recruit DNA polymerase alpha to chromatin for initiation of DNA replication. Genes Dev. 2007;21(18):2288-99.

34. Sato N, Koinuma J, Fujita M, Hosokawa M, Ito T, Tsuchiya E, Kondo S, Nakamura Y, Daigo Y. Activation of WD repeat and high-mobility group box DNA binding protein 1 in pulmonary and esophageal carcinogenesis. Clinical Cancer Res Official J American Association Cancer Res. 2010;16(1):226-39

35. Esposito F, Tornincasa M, Federico A, Chiappetta G, Pierantoni GM, Fusco A. High-mobility group A1 protein inhibits p53-mediated intrinsic apoptosis by interacting with $\mathrm{BCl}-2$ at mitochondria. Cell Death Dis. 2012;3:e383.

36. Park SY, Im JS, Park SR, Kim SE, Wang HJ, Lee JK. Mimosine arrests the cell cycle prior to the onset of DNA replication by preventing the binding of human Ctf4/And-1 to chromatin via Hif-1alpha activation in HeLa cells. Cell Cycle. 2012;11(4):761-6.

37. Zhou Y, Zhang Q, Gao G, Zhang X, Liu Y, Yuan S, Wang X, Chen JJ. Role of WDHD1 in Human Papillomavirus-Mediated Oncogenesis Identified by Transcriptional Profiling of E7-Expressing Cells. J Virol. 2016;90(13):6071-84.

38. Darnell JE Jr. STATs and gene regulation. Science. 1997;277(5332):1630-5.

39. Wang J, Li X, Lu X, Pi L: [The regulation of stat3 signal transduction pathway to G1 to $S$ phase of laryngocarcinoma cell]. Lin chuang er bi yan hou tou jing wai ke za zhi = Journal of clinical otorhinolaryngology, head, and necksurgery 2008, 22(15):699-703.

40. Shields BJ, Tiganis T. Replication checkpoint control by a PTK/STAT3/cyclin D1 axis. Cell Cycle. 2009;8(2):223-30.

41. Koganti S, de la Paz A, Freeman AF, Bhaduri-Mclntosh S. B lymphocytes from patients with a hypomorphic mutation in STAT3 resist Epstein-Barr virus-driven cell proliferation. J Virol. 2014;88(1):516-24.

42. Yang E, Lerner L, Besser D, Darnell JE Jr. Independent and cooperative activation of chromosomal c-fos promoter by STAT3. J Biol Chem. 2003;278(18):15794-9.

43. Lo HW, Hsu SC, Xia W, Cao X, Shih JY, Wei Y, Abbruzzese JL, Hortobagyi GN, Hung MC. Epidermal growth factor receptor cooperates with signal transducer and activator of transcription 3 to induce epithelialmesenchymal transition in cancer cells via up-regulation of TWIST gene expression. Cancer Res. 2007;67(19):9066-76.

44. Aggarwal BB, Sethi G, Ahn KS, Sandur SK, Pandey MK, Kunnumakkara $A B$, Sung $B$, Ichikawa $H$. Targeting signal-transducer-and-activator-oftranscription-3 for prevention and therapy of cancer: modern target but ancient solution. Ann N Y Acad Sci. 2006;1091:151-69.

45. Jung JE, Lee HG, Cho IH, Chung DH, Yoon SH, Yang YM, Lee JW, Choi S, Park JW, Ye SK, et al. STAT3 is a potential modulator of HIF-1-mediated VEGF expression in human renal carcinoma cells. FASEB J Off Publ Federation American Societies Exp Biol. 2005;19(10):1296-8.

46. Leslie K, Lang C, Devgan G, Azare J, Berishaj M, Gerald W, Kim YB, Paz K, Darnell JE, Albanese C, et al. Cyclin D1 is transcriptionally regulated by and required for transformation by activated signal transducer and activator of transcription 3. Cancer Res. 2006;66(5):2544-52.

47. Sinibaldi D, Wharton W, Turkson J, Bowman T, Pledger WJ, Jove R. Induction of p21WAF1/CIP1 and cyclin D1 expression by the Src oncoprotein in mouse fibroblasts: role of activated STAT3 signaling. Oncogene. 2000;19(48):5419-27.

48. Liu B, Hu Y, Qin L, Peng XB, Huang YX. MicroRNA-494-dependent WDHDI inhibition suppresses epithelial-mesenchymal transition, tumor growth and metastasis in cholangiocarcinoma. Dig Liver Dis. 2019;51(3):397-411.

49. Zhou Y, Pei F, Ji M, Zhang F, Sun Y, Zhao Q, Wang X, Hong Y, Tian J, Wang Y et al: WDHD1 facilitates G1 checkpoint abrogation in HPV E7 expressing cells by modulating GCN5. BMC Cancer 2020, 20(1):840.56.

50. Yuan J, Zhang F, Niu R. Multiple regulation pathways and pivotal biological functions of STAT3 in cancer. Sci Rep. 2015;5:17663.

51. Johnson DE, O'Keefe RA, Grandis JR. Targeting the IL-6/JAK/STAT3 signalling axis in cancer. Nature Rev Clin Oncol. 2018;15(4):234-48.

52. Hsieh CL, Lin CL, Liu H, Chang YJ, Shih CJ, Zhong CZ, Lee SC, Tan BC. WDHD1 modulates the post-transcriptional step of the centromeric silencing pathway. Nucleic Acids Res. 2011;39(10):4048-62.

53. Jaramillo-Lambert A, Hao J, Xiao H, Li Y, Han Z, Zhu W. Acidic nucleoplasmic DNA-binding protein (And-1) controls chromosome congression by regulating the assembly of centromere protein $A(C E N P-A)$ at centromeres. J Biol Chem. 2013;288(3):1480-8.

54. Chen Y, Liu H, Zhang H, Sun C, Hu Z, Tian Q, Peng C, Jiang P, Hua H, Li X, et al. And-1 coordinates with CtIP for efficient homologous recombination and DNA damage checkpoint maintenance. Nucleic Acids Res. 2017:45(5):2516-30. 
55. Li Y, Li Z, Wu R, Han Z, Zhu W. And-1 is required for homologous recombination repair by regulating DNA end resection. Nucleic Acids Res. 2017;45(5):2531-45.

56. LiY, Jaramillo-Lambert AN, Yang Y, Williams R, Lee NH, Zhu W. And-1 is required for the stability of histone acetyltransferase Gcn5. Oncogene. 2012;31(5):643-52.

57. Sun S, Zhang X, Xu M, Zhang F, Tian F, Cui J, Xia Y, Liang C, Zhou S, Wei H et al. Berberine downregulates $C D C 6$ and inhibits proliferation via targeting JAK-STAT3 signaling in keratinocytes. Cell Death Dis. 2019;10(4):274.
58. Kim J, Kim D, Chung J. Replication protein a 32 kDa subunit (RPA p32) binds the SH2 domain of STAT3 and regulates its transcriptional activity. Cell Biol Int. 2000;24(7):467-73.

\section{Publisher's Note}

Springer Nature remains neutral with regard to jurisdictional claims in published maps and institutional affiliations.
Ready to submit your research? Choose BMC and benefit from:

- fast, convenient online submission

- thorough peer review by experienced researchers in your field

- rapid publication on acceptance

- support for research data, including large and complex data types

- gold Open Access which fosters wider collaboration and increased citations

- maximum visibility for your research: over $100 \mathrm{M}$ website views per year

At BMC, research is always in progress.

Learn more biomedcentral.com/submissions 